\title{
Registro de eventos de alocação de contêineres em Blockchain
}

\author{
Marco A. Marques ${ }^{1}$, Charles C. Miers ${ }^{1}$ \\ ${ }^{1}$ Programa de Pós-Graduação em Computação Aplicada (PPGCA) \\ Universidade do Estado de Santa Catarina (UDESC) - Joinville, SC - Brasil \\ marco.marques@edu.udesc.br, charles.miers@udesc.br
}

\begin{abstract}
Container-based virtualization technology enables dynamic allocation, addressing needs of escalability. This feature provides greater flexibility in the use of computing resources, but turns monitoring a challenge due to the large flow of calls and allocations. This article proposes a solution concept of Blockchain-based container tracking for allocation / de-allocation. Recording these operations in a Blockchain allows to not only audit the resources employed but also the cronology analysis of the performed operations.
\end{abstract}

\section{Introdução}

A arquitetura de microsserviços permitiu aumentar o desempenho de software, fragmentando-o em partes independentes de desenvolvimento, versionamento, deploy e escalabilidade [Jamshidi 2018]. Contêineres são considerados o padrão de microsserviços na nuvem [Vaucher 2018]. Dentre as suas principais características destacam-se a rapidez e facilidade na alocação, escalabilidade e resiliência [Newman 2015].

A orquestração de contêineres permite que desenvolvedores definam como coordenar o funcionamento em ambientes de nuvem de aplicações baseadas em múltiplos contêineres, moldando um ambiente dinâmico, mas de difícil monitoramento. Com base neste cenário, foram desenvolvidas ferramentas para registro de eventos de contêineres em base de dados tradicionais.

Este trabalho apresenta o uso de Blockchain como alternativa ao registro nestas bases, por trazer características como encadeamento criptográfico, descentralização e imutabilidade, permitindo auditar a utilização dos recursos computacionais de forma cronológica, confiável e segura.

\section{Motivação e Proposta}

Há duas abordagens possíveis, sendo a primeira ativa, na qual cada contêiner é responsável por gerar a transação que irá registrar em Blockchain sua alocação, e a segunda passiva, quando o registro é realizado pelo orquestrador.

A solução proposta adotará a opção passiva, com o objetivo de não consumir recursos dos contêineres, além de facilitar a implementação e gestão do ambiente. Será empregado um Blockchain que pode ser Privado ou Consórcio, composto de $n$ nós validadores, que receberão transações de um plugin acoplado ao orquestrador de contêineres. Estas transações, geradas sempre que o orquestrador alocar ou desalocar um contêiner, serão validadas pelos nós e inseridas na cadeia de blocos. Os orquestradores são responsáveis pelo gerenciamento do ciclo de vida dos contêineres, atuando da alocação à finalização, sendo ideais para acionar o evento que irá gerar a transação. A solução proposta utiliza o orquestrador de contêineres Docker Swarm e o conceito de Blockchain 
será implementado através da solução Hyperledger (https://www.hyperledger.org/). A Figura 1 apresenta um caso de uso de alocação de contêiner.

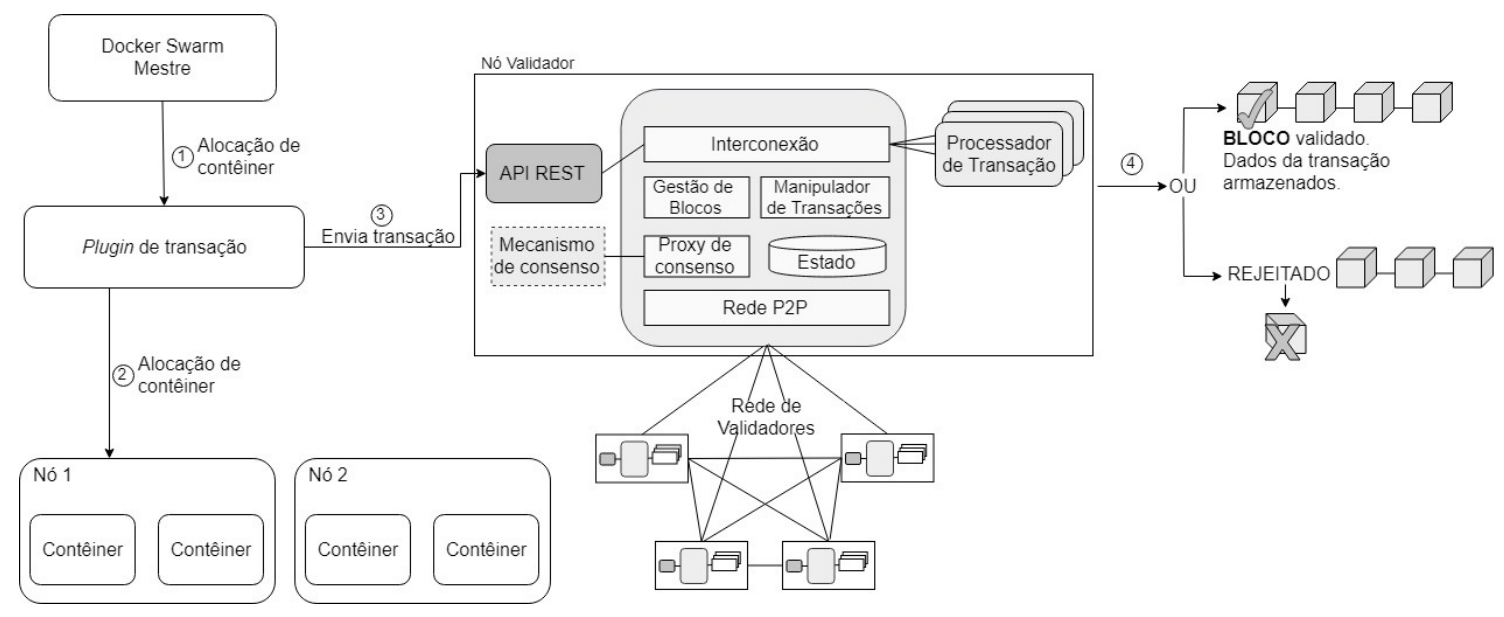

Figura 1. Caso de uso de alocação de contêiner.

Na Figura 1, o Docker Swarm, ao alocar um contêiner, aciona o plugin (1) responsável por gerar uma transação contendo os dados do contêiner e enviá-la ao nó validador (2). Após o procedimento de validação o bloco gerado é adicionado à Blockchain ou descartado (3). Busca-se, com a utilização da Blockchain, mecanismos que garantam a disponibilidade e confiabilidade dos registros, oferecidos através de armazenamento seguro e auditável, encadeamento criptográfico, descentralização e imutabilidade.

\section{Considerações e Trabalhos futuros}

O plugin responsável pelas transações deverá ser capaz de atender a todas as chamadas realizadas pelo orquestrador. A quantidade de nós validadores que compõem a rede de validadores deverá considerar o grau de descentralização, disponibilidade e segurança exigidos.

As próximas etapas consistem em montar um cenário de testes, desenvolver o plugin para o orquestrador e implementar uma Blockchain utilizando a solução Hyperledger em ambiente virtual de contêineres. Isto permitirá avaliar, além da viabilidade técnica, justificar o uso de Blockchain em relação a abordagens tradicionais.

Agradecimentos: Os autores agradecem ao LabP2D, UDESC e FAPESC.

\section{Referências}

Jamshidi, P. e. a. (2018). The journey so far and challenges ahead. IEEE Software, 35(3):24-35.

Newman, S. (2015). Building Microservices. OReilly, 1 edition.

Tasca, P., T. C. J. (2019). A taxonomy of blockchain technologies: Principles of identification and classification. Ledger Journal, 4:1-39.

Vaucher, S. e. a. (2018). Sgx-aware container orchestration for heterogeneous clusters. In Proc. of 38th ICDCS. IEEE 38th Int. Conference Distrib. Comput. Syst. (ICDCS).

Zheng, Z., X. S. D. H.-N. C. X. and Wang, H. (2018). Blockchain challenges and opportunities: a survey. Int. J. Web and Grid Services, 14(4):352-375. 